\title{
Sobre uma visita: Alphonsus de Guimaraens e o Modernismo
}

\author{
Leopoldo Comitti \\ Universidade Federal de Ouro Preto
}

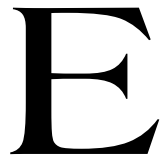

m 1919, Mário de Andrade faz uma visita ao poeta simbolista Alphonsus de Guimaraens, então residindo em Mariana. Por esta época, o boêmio autor de versos algo satânicos dos tempos da Faculdade de Direito de São Paulo, já casado, cheio de filhos e maduro, não mais existia. Raramente saía da pequena cidade mineira, mesmo instado pelos amigos, tais como Freitas Valle, que lhe enviava cartas e convites para seus concorridos saraus literários. Porém, mesmo isolado, exercia forte impacto nos meios literários de Rio e São Paulo, especialmente naqueles que, insatisfeitos com a literatura oficial dos parnasianos e naturalistas, buscavam novos caminhos a percorrer.

O encontro entre os dois poetas e o deslumbramento do jovem pela obra do mais velho está registrado também no magnífico poema de Carlos Drummond de Andrade intitulado "A visita". Poema narrativo e denso, extrai do diálogo entre duas gerações lições de poesia e demonstra toda a reverência modernista a um autor ligado a uma poética anterior, porém jamais repudiada pelos jovens revolucionários:

$\mathrm{O}$ alto visitante jovem inclina-se, compenetrado:

- O Príncipe não é príncipe, eu sei, para o distraído, fosfóreo descaso dos donos da literatura e da vida. 
mas é bem mais do que isso, para cada um de nós poucos obcecados pela vertigem do poema no cristal da linguagem. ${ }^{1}$

O poema, além de soberba homenagem, pontua delicadamente a herança deixada pelos simbolistas aos jovens e inquietos artistas da geração de 20 que, apesar de anunciarem um repúdio total ao passado e à tradição, mantêm relações estreitas com o Simbolismo, colocando em destaque Cruz e Souza e Alphonsus de Guimaraens. Assim, o poema de Drummond, passado o momento revolucionário, faz um balanço de heranças e convergências. E não poderia ser diferente, pois o próprio Mário de Andrade, em artigo de 1919, para A Cigarra, escrito após uma visita a Alphonsus, em Mariana, declara:

Não haverá no Brasil um editor que lhes agasalhe os poemas, tirando-os da escuridão? Não existirá a piedade dum povo bandeirante que vá descobrir nas Minas Gerais essa mina de diamantes castiços e lapidados, e deslumbre os da nossa raça com os tesoiros que Alphonsus guarda junto de si? Onde? quando o abrete Sésamo dessa gruta encantada? ... ${ }^{2}$

Se Mário de Andrade registra o encontro com tal ênfase e deslumbramento, não se pode dizer que Alphonsus tenha sentido menor impacto; apenas o menciona com a moderação própria de sua correspondência, em uma carta, datada de 15 de julho de 1919, para seu filho João Alphonsus, então residindo em Belo Horizonte, na qual comenta o mesmo fato:

Há cinco dias esteve aqui o Sr. Mário de Morais Andrade, de S. Paulo, que veio apenas para conhecer-me, conforme disse. É doutor em ciências filosóficas. Leu e copiou várias poesias minhas (principalmente as francesas), e admirou o teu soneto oferecido ao Belmiro Braga. É um rapaz de alta cultura, sabendo de cor, em

\footnotetext{
${ }^{1}$ ANDRADE, 1992. p. 761. O poema "A visita" também pode ser encontrado em edição restrita, publicado por José Mindlin e Antônio Marcos da Silva, em 1977, com exemplares numerados e autografados por Drummon. No Museu Casa Alphonsus de Guimaraens, encontra-se o exemplar de número 55. ${ }^{2}$ Apud GUIMARAENS FILHO, 1995. p. 358.
} 
inglês, todo o "Corvo" de Poe. Viaja para fazer futuras conferências, e visitou todos os velhos templos desta cidade.

A verdade é que, para quem vive, como eu, isolado - uma visita dessas deixa profunda impressão. ${ }^{3}$

Certamente, da parte de Mário de Andrade, esse encontro era extremamente esperado. Freqüentador dos saraus literários da Villa Kyrial, juntamente com outros modernistas, tais como Oswald de Andrade, Guilherme de Almeida e Anita Malfatti, conhecia não apenas a obra de Alphonsus, mas também o extremo valor que o anfitrião, Freitas Valle (literariamente Jacques D’ Avray), atribuía ao amigo, companheiro em sua juventude de vida boêmia e tertúlias literárias.

Também Oswald de Andrade, apesar de toda sua radicalidade anti-passadista, em 1921, ao comentar o falecimento do poeta, reitera sua importância, destacando sua grandeza e importância para a Literatura Brasileira:

Hoje que uma estuante geração paulista quebra nas mãos a urupuca de taquara dos versos medidos, a figura de Alphonsus de Guimarães assume a sua inteira grandeza no movimento da boa arte nacional (...).A reação por ele iniciada contra a incultura e o atraso dos nossos principais poetas está sendo rigorosamente continuada (...). Poetas como ele honram não só uma geração como uma pátria. ${ }^{4}$

Podemos perceber que, se a crítica insistiu em passar ao largo da obra do escritor, o mesmo não aconteceu com relação aos poetas modernistas, que, quase unanimemente, o aclamaram e, nas linhas ou entrelinhas, reconheceram em sua poesia o início de uma inquietação lírica que se iria consagrar apenas após o Movimento Modernista de 1922. Não é de se estranhar, pois, que um dos poucos estudos mais aprofundados da poesia de Alphonsus tenha sido escrito justamente por Henriqueta Lisboa, ${ }^{5}$ poeta mineira que sempre lhe atribuiu sua iniciação literária.

${ }^{3}$ GUIMARAENS, 1960. p. 672.

${ }^{4}$ Apud GUIMARAENS FILHO, 1995. p. 367.

${ }^{5}$ LISBOA, 1945. 
Nas décadas de 40 e 50, como já observamos, há um número maior de textos a ele dedicados, mas são ainda os poetas modernistas que insistem em revivê-lo, como o faz Manuel Bandeira, em texto de 1953: "Se fosse vivo, completaria hoje (...) setenta e três anos. Se fosse vivo... Em verdade vivo ele está e cada vez mais no afeto e na admiração de todos os brasileiros". ${ }^{6}$

A necessidade de Bandeira em reafirmar a presença do ausente já evidencia uma situação que se configurou logo após a morte do poeta, em 1921, ou seja, o fato de seu nome e sua propalada importância sobrepujarem a obra. Dele ficou o nome (registrado em ruas, pontes, bibliotecas), acrescido da expressão qualificativa "grande poeta". Os poemas caíram no esquecimento, exceção feita aos poucos que podemos denominar "antológicos". Percebemos que, mesmo ao destacá-lo, nossos modernistas não se arriscam muito além das menções evasivas e generalistas. Em que elementos, então, podemos entrever a contribuição de Alphonsus de Guimaraens para a eclosão do Movimento de 1922?

Certamente os elogios não seriam mera deferência ao pai de João Alphonsus, escritor fundamental para a constituição do grupo modernista mineiro. Também não seriam resultado da convivência com Freitas Valle, nem simples respeito aos simbolistas, marginais em relação ao Parnasianismo (alvo preferencial das diatribes dos jovens). Obviamente essas seriam respostas simplistas, especialmente se nos lembrarmos de que a visita de Mário de Andrade a Mariana foi realizada em 1919. Talvez as já mencionadas palavras do próprio Alphonsus a esse respeito possam elucidar um pouco melhor a questão. Obviamente, o poeta mais velho percebeu de imediato uma identificação. A profunda impressão não advém apenas do alegado isolamento, mas também dos interesses comuns, tais como a poesia de Edgar Allan Pöe e a arte religiosa colonial. Encontram-se aí dois elementos de extrema significação para as vanguardas brasileiras, se lembrarmos dos aspectos composicionais

${ }^{6}$ Apud GUIMARAENS FILHO, 1995. p. 365. 
do poeta norte-americano e a valorização da arte barroca, especialmente salientada na viagem dos modernistas, acompanhando Blaise Cendrars, em 1924.

Já em 1919, Mário de Andrade antevia, por meio desta visita a Alphonsus de Guimaraens, duas discussões que acompanham todo o século XX, mas que ganham maior destaque por parte da crítica literária brasileira apenas na passagem dos anos 50 para 60, com os debates suscitados pelas tendências oriundas do concretismo, observadas especialmente na obra de Haroldo de Campos.

Tais questões nos fazem pensar em uma confluência de experiências novas de ambos os poetas: no Mário Sobral (algo parnasiano), que dá lugar ao Mário de Andrade modernista, e no Alphonsus que vai perdendo cada vez mais o hermetismo dos primeiros textos e parece dar uma nova cadência ao ritmo simbolista e intensificar experiências com versos livres, como percebemos nos últimos poemas de Pulvis.

As já anteriormente mencionadas alegações de uma estreita relação entre brasileiros e as novidades européias são suficientes para justificar o interesse tão próximo. Compreendemos que o vigor da poesia de Alphonsus, capaz de maravilhar Mário, nem de longe passa pelos arroubos ultra-românticos ainda presentes no início de sua obra, período muito marcado pelo impacto da morte prematura do noiva, motivo de um certo luto estético-mórbido amoroso. Esses primeiros experimentos explodirão em novas concepções literárias, quando já imerso na boêmia característica de sua passagem pelas Arcadas da Faculdade de Direito de São Paulo. Nesse momento, a tradição local (Faculdade de Direito em São Paulo), a tradição religiosa, e a formação intelectual advinda de uma tradição familiar pré-romântica e romântica produzem um deslocamento estranho em relação à produção de seus contemporâneos que não passa despercebida à crítica modenista.

Assim, o poeta que Mário visita não é simplesmente um poeta simbolista, mas, como declara o próprio Alphonsus, alguém que reúne às qualidades de seu grupo outras possibilidades de desdobramentos, alguns advindos de uma formação sólida quanto aos clássicos. Isto fica evidenciado em sua biblioteca, pois os títulos 
lá reunidos demonstram grande interesse pelos mesmos, em especial por Dante, não apenas pelas duas diferentes edições de O Inferno, como também por conter, na parte iconográfica, reproduções de ilustrações da obra maior do poeta italiano. Certamente, tal fato abre espaço para relevantes estudos das relações intertextuais entre as obras dos dois poetas. Em outro momento, em sua correspondência com o acadêmico Mário de Alencar (quando ambos trocam textos e sugerem emendas), Alphonsus deixa registrado seu apreço por Dante:

Quanto ao que me dizes sobre "Vendo-te Rezar", muito bem. Enviote alterado, e mesmo assim não o suponho perfeito. Notaste tudo quanto nele havia de pior. - "O Caronte Infernal etc." Dando a expressão de ilusório a Letis, isto é, vão, falso, quis dizer com o $3^{\circ}$ e $4^{\circ}$ versos que o inferno, o purgatório estão neste mundo - idéia, aliás, já velha. ${ }^{7}$

Sem dúvida, a presença do Inferno se dissemina por toda a obra do escritor. Mais que um simples elemento temático comum à poesia mística, necessariamente relacionado à morte, tema tão caro a seus seus contemporâneos simbolistas, acaba por se tornar uma das linhas de força da tensão que percorre a obra. Lida em sua totalidade, podemos depreender dela quase um drama (talvez fosse melhor mencionar tragédia), em que a noiva morta ainda jovem assombra a existência. Não por uma saudade, ou a permanência de um amor juvenil, mas por enfatizar a tensão entre o pleno equilíbrio e ausência de dor inerentes à morte e o sobressalto constante de uma vida atribulada que faz o homem pagar seu tributo às necessidades materiais.

Assim, torna-se mais significativa a ausência de D. Zenaide, a esposa, na obra de Alphonsus. A poesia está imune ao gineceu, onde domina a esposa em sua materialidade gritante, tão gritante que se manifestará ainda mais após o falecimento de ambos. Para Alphonsus, o poema cria um espaço pequeno, quase uma janela que o faz divisar o perfeito equilíbrio da morte, sintetizado na imagem

\footnotetext{
${ }^{7}$ GUIMARAENS, 1960. p. 667.
} 
da adolescente defunta (evocada por Constancinha) que paira além do tempo, em sua pureza utópica e nebulosa, eternamente congelada no momento estético em que a dor se finda. Sem dúvida, a poesia de Alphonsus fala de dores e sombras, mas de dores e sombras que mais se agudizam por vislumbrar o eterno e deter o passo que pode levá-lo a cruzar o umbral. Aqui, percebemos o conflito entre uma formação religiosa cristã, que compreende a morte como julgamento, e uma opção pela concepção esotérica, que a vê como uma simples passagem que livrará a alma do cárcere representado pelo corpo físico sujeito aos tormentos da vida prática.

A obra de Alphonsus oferece inúmeras tensões semelhantes, que certamente a destacam de uma estética simbolista estreita. Se a tem como um horizonte, não a leva demasiadamente a sério, como aliás declara a Mário de Alencar, em carta datada de 02 de agosto de 1908: “(...) para alguns mostraste a má vontade que tens a uma escola a que me filiei, mas da qual só tenho aproveitado o que há nela de bom e razoável, sem exageros pindáricos, nem alcandorações gongóricas... ${ }^{8}$

Seria unicamente um eclético, como seu correspondente? Ou alguém que, na busca de um melhor resultado poético, não hesita em lançar mão de recursos heterogênios, que já despontam nesse 1919, como uma das práticas experimentais dos nossos modernistas? Seu diálogo com João Alphonsus, seu filho, nos faz crer que, pelo menos de forma tímida, já dava alguns passos em direção ao grupo que eclodiu em 22: "O teu soneto humorístico irá para "O Alfinete" e o outro para o "Germinal". Não sei onde pus aquele outro, em que empregavas o part. passado expansas, de cuja vernaculidade duvidei, não tendo um Dic. Latino para consultar." ${ }^{9}$ Em 1918, em carta a Belmiro Braga, já elogiava o filho de apenas 17 anos, encaminhando um texto de João Alphonsus para publicação:

\footnotetext{
${ }^{8}$ GUIMARAENS, 1960. p. 667.

${ }^{9}$ GUIMARAENS, 1960. p. 673.
} 
Segue mais um - "O Sino" -, inédito também, e outro do João, escrito aqui um dia antes, que lhe é oferecido. Pondo de lado minha natural suspeição, parece-me que posso afirmar que temos mais um poeta. Ele já faz muito pela idade que tem. Nasceu em $1901 .{ }^{10}$

Evidentemente, por este tempo João Alphonsus ainda não era o modernista que viria a ser depois, porém nessa acolhida ao filho, bem como a outros novos escritores que a ele submetiam os textos, podemos sentir um crescente interesse pelos experimentos de uma nova geração, expressivamente distanciada da sua.

Da tradição familiar (poderíamos dizer que os Guimarães formam um clã literário em Minas) e escolar, sem dúvida aproveita com grande apuro algumas lições, tais como a prática de humor e sátira típica dos pré-românticos e românticos mineiros, notadamente o Padre Correia de Almeida, e, especialmente, Bernardo Guimarães. Do parente próximo estetiza, em curtos textos humorísticos, a ironia e a irreverência, além do ritmo e certas técnicas expressivas populares (que valeram a Bernardo severas críticas). Assim, em contraponto a uma lírica impregnada de sacralidade - às vezes ultra-romântica, outras de um tom francamente barroquista -, Alphonsus constrói um texto paródico instigante, que prenuncia as experiências modernistas da década de 20, tais como um epigrama que, apesar dos moldes da forma tradicional, já lembra o poema-piada:

\section{Epigrama}

Na próxima revisão eleitoral, serão suprimidos das listas todos os eleitores mortos (De um jornal).

Empreguei a medicina

Para fins eleitorais...

Ai de mim! ai triste sina!

Os mortos não votam mais.

Dr. Rapadura ${ }^{11}$

\footnotetext{
${ }^{10}$ GUIMARAENS, 1960. p. 669.

${ }^{11}$ GUIMARAENS, 1960. p. 589.
} 
Evidentemente, sem ainda o experimentalismo extremo da década de 20, percebemos um abandono gradativo do nosso exótico esteticismo simbolista, ainda mesclado de práticas parnasianas, e a eleição de um texto que vai buscar na fala popular formas de expressão diretas, utilizadas de maneira bastante sintética, em que a participação sócio-política está presente, mais ou menos aos moldes do mestre Correia de Almeida. Das questiúnculas de uma pequena cidade, faz alusão não somente a questões mais gerais da política brasileira, como também da própria atuação irônica do homem, frente à banalidade do cotidiano.

Mário de Andrade certamente descobriu o "abre-te-Césamo da Gruta Encantada". Podemos perceber tal fato especialmente em 1924, quando insere em "Noturno de Belo Horizonte" a lenda da Serra do Rola-Moça. ${ }^{12}$ Nele, determinadas passagens lembram recursos expressivos comuns a Alphonsus, além de buscar tematicamente se referir a outra de suas viagens a Minas. Ecos do mestre visitado parecem às vezes soar em sua obra: notadamente na linguagem popular despojada (e até rude, às vezes), da poesia satírica; ou os ritmos mais sutis e elaborados, de "A Catedral" e "Ismália". Certamente, em 1919, na casa de Alphonsus de Guimaraens, Mário percebe vitalidade na tradição e inicia um intenso diálogo com os poetas mineiros. Diálogo esse que duraria por toda sua vida.

Carlos Drummond de Andrade, talvez o modernista mais comprometido com tal tradição, percebe de imediato a importância do encontro e, de certa forma, aponta para o leitor novas possibilidades de interpretação das vanguardas do início do século. Já José Mindlin e Antônio Marcos da Silva, com uma edição rara e seleta de "A Visita", ${ }^{13}$ pinçam da obra do itabirano justamente o texto que acerta as contas com o passado, demonstrando que, também no Brasil, o século XX auferiu todos os lucros possíveis do simbolismo e do decadentismo.

\footnotetext{
12 ANDRADE, 1980. p. 132-133.

${ }^{13}$ ANDRADE, 1977.
} 


\section{Referências Bibliográficas}

ANDRADE, Carlos Drummond de. A visita. São Paulo: Edição privada de José Mindlin e Antônio Marcos da Silva, 1977.

ANDRADE, Carlos Drummond de. Poesia e prosa. Rio de Janeiro: Nova Aguilar, 1992.

GUIMARAENS, Alphonsus de. Obra completa de Alphonsus de Guimaraens. Rio de Janeiro: José Aguilar, 1960.

GUIMARAENS FILHO, Alphonsus. Alphonsus de Guimaraens em seu ambiente. Rio de Janeiro: Biblioteca Nacional, 1995.

LISBOA, Henriqueta. Vida e obra de Alphonsus de Guimaraens. Rio de Janeiro: Agir, 1945.

\section{Resumo}

Este ensaio discute aspectos de recepção da obra de Alphonsus de Guimaraens no século XX. Coloca em evidência o diálogo entre o poeta simbolista e Mário de Andrade (1919), relatado no poema "A Visita", de Carlos Drummond de Andrade.

\section{Abstract}

This essay discusses reception aspects of the Alphonsus de Guimaraens' work in the $20^{\text {th }}$ century. It places in evidence the dialogue among the simbolist poet and Mário de Andrade (1919), related in the poem $A$ Visita ("The Visit") by Carlos Drummond de Andrade. 